\title{
Development of Online Counseling System and Usability Evaluation
}

\author{
Chieko Kato \\ Faculty of Information Sciences and Arts, Toyo University, Kawagoe, JAPAN \\ Email: kato-c@toyonet.toyo.ac.jp \\ Yasunori Shiono \\ Faculty of Information Sciences and Arts, Toyo University, Kawagoe, JAPAN \\ Email: shiono@toyo.jp \\ Takaaki Goto \\ Center for Industrial and Governmental Relations, The University of Electro-Communications, Chofu, JAPAN \\ Email: goto@kikou.uec.ac.jp \\ Kensei Tsuchida \\ Faculty of Information Sciences and Arts, Toyo University, Kawagoe, JAPAN \\ Email: kensei@toyonet.toyo.ac.jp
}

\begin{abstract}
Rising prevalence of mental health diseases is a serious problem for society. Some areas in Asia have no medical facilities and proper mental health care is unavailable. To cope with these problems, application of ICT for mental health services has been recognized as one of the effective approaches. Therefore, we have been studying and putting into practice online counseling for people assigned overseas. We constructed a system using agile software development for those assigned overseas in Asia. The first step involved developing a prototype system based on system requirements after we repeatedly discussed system development with people in charge of a clinic. Next, we conducted interviews about the online counseling system. We also discussed and analyzed the interviews. Finally, we completed the online Web counseling system by repeatedly discussing possible improvements with the clinic and then incorporating the changes in the system. Moreover, we evaluated the system by conducting a survey in the form of a questionnaire. Since we developed an effective online counseling system using statistical methods, this paper reports on the construction and usability evaluation of the system.
\end{abstract}

Index Terms-online web counseling system, mental health care, agile software development, user-centered design, usability evaluation

\section{INTRODUCTION}

The total number of Japanese who stay in foreign countries is now over 1 million, and that number is increasing year after year. In particular, the number of Japanese staying in Asian countries including China has expanded rapidly. The suicide rate of those on overseas assignments exceeds the mortality rate that is due to traffic accidents

This paper is based on "Development of Web Counseling System," by Yasunori Shiono, Takaki Goto, Tetsuro Nishino, Chieko Kato and Kensei Tsuchida, which appeared in the Proceedings of the 12th International Conference on Network-Based Information Systems, pp. 370-375, IEEE Computer Society, August 2009. and crime. The risk of suffering mental health problems is somewhat high, due to problems such as working away from home, language barriers, and differences in culture, human relationships, and medical facilities. Some areas of Asia have no medical facilities, and proper mental health care is unavailable. Therefore, online counseling systems are needed. So far there is some research about online counseling systems $[1,2]$ and mental health care systems [3]. We have been studying and putting into practice online counseling for people assigned overseas $[4,5,6]$

Various technologies are being developed in the computer industry. Among them, online services and systems have been proposed in many fields. E-health is one example of this [7]. User satisfaction and cost-cutting are also becoming increasingly important. In some cases, however, communication between IT engineers and mental health specialists did not go well and then the system developed was not easy for users to use. Therefore, user-centered design (UCD) involving IT engineers and mental health specialists is necessary [8]. Agile software development based on UCD has received a lot of attention [9, 10, 11, 12, 13]

In our study, we aim to prevent mental health problems from worsening as a result of negligence for those assigned overseas in Asia. Therefore we constructed an online web counseling system in cooperation with a clinic by agile software development based on UCD. Moreover, we evaluate the system by conducting a survey in the form of a questionnaire. In this paper we developed an effective online counseling system using statistical methods, we report on the development of the system, describe the system itself and evaluate the system.

The rest of this paper is organized as follows. We explain how the system is developed in Section 2. In Section 3, we describe our online Web counseling system, 
focusing on who the authorities are and what functions they have. Moreover, in Section 4, we evaluate the system by conducting a survey in the form of a questionnaire. Finally, in Section 5, we conclude the paper.

\section{Development With Agile Methods}

Ordinary users can access the online Web counseling system. During the development, we needed to decide on specifications that satisfy the needs of counselors and clients for high phases of the software life cycle. Since the online counseling system is used by end-users who are not experts, it is important to discuss the gratifying specifications reflected via end-user demands. Therefore, UCD was desired. To construct a system incorporating UCD, we developed an online web counseling system in cooperation with a clinic using agile software development.

In cooperation with a psychiatric clinic, concrete requirements are created by communicating with psychological counselors and patients. One of the agile methodologies iterates the analysis phase and the design phase based on user evaluation until user needs are reflected, unlike in the case of traditional development. In the case of this project, the following phases are iterated until users are satisfied.

- Reanalysis based on results of evaluation of analysis by users.

- Redesign based on results of evaluation of analysis by users.

Agile software development also has the following features.

- Iterations of analysis and design.

- People-to-people exchange.

- Response to changes.

- Bolstering cooperation with customers.

- Release of available software at the end of each iteration.

We believe that an effective counseling system reflected the needs of counselors and clients by incorporating the above features. In view of the agile methodologies and features, the development flow is as follows.

Development flow:

Stage 1. Develop a prototype system based on system requirements.

Stage 2. Conduct interviews about the system.

Stage 3. Discuss and analyze the interviews.

Stage 4. Complete the system based on the content of the interviews.

In each stage, we repeatedly discussed and analyzed these issues with the people in charge of the clinic. In addition, we evaluated the completed system.

The first step involved developing a prototype system based on system requirements after we repeatedly discussed system development with people in charge of the clinic. Next, we conducted interviews about the online counseling system. We also discussed and analyzed the interviews. Finally, we completed the system by repeatedly discussing possible improvements with the clinic and then incorporating the changes in the system.

\section{A. System Requirements}

In the first stage, we summarized the system requirements by repeatedly discussing system development with the people in charge of the clinic. Some of the important system requirements were as follows:

- Since confidentiality of counseling content is important and the content is strictly secret, the system prevents information from leaking.

- User interface: Page color and layout.

- Basic functions: PDF uploading/downloading and $\log$ function.

We had requirements for system confidentiality, user interface and basic functions such as personal information protection, page color and PDF uploading/downloading.

Based on the above system requirements, we summarized system requirements specifications and had the two important system requirement items:

- Mail counseling should be managed by one mail server, since confidentiality of counseling content is important and encrypting mail server communication is difficult.

- The server should be managed by an associate member since outside contractors increase the risk of leaking counseling content.

Because the confidentiality of counseling content is very important, mail counseling managed by one mail server is needed. The reason is that encrypting mail server communication is difficult. That counseling content may be leaked by intercepting mail server communications. The reason for server management being done by associate members is that outside contractors increase the risk of leaking counseling content. In fact, we constructed the servers by using open source software. The reason why the system is developed by open source software is that users gain peace of mind from knowing that developers constructed the system not as a black box system, and responsibility for their responses in every situation remains inside the system. We developed a prototype system based on these system requirement specifications.

\section{B. Interviews Regarding the Overall Image of Online Counseling}

Seven people were interviewed before starting the online counseling system. The seven people are carefully selected for effective counseling system. The selection is determined based on the folloing:

- The person is interested in counseling.

- The person have used computers.

- The person can promote people-to-people. 
- The person gives permission to disclose personal information for our study activities as necessary.

The following questions were asked.

1. What do you think of online counseling?

2. What information do you want to know when you use online counseling?

3. Do you have any concerns regarding the security of online counseling?

4. What do you think of our online counseling system?

We tabulated the results in Table I. A few things were discovered from the results of the interviews. Generally, people had a good impression of online counseling, and nobody had a bad impression. Most people wanted to know about their counselor's background, especially because they could not see their counselor's face and because they were revealing many sensitive personal things.

With face-to-face counseling, information can easily be kept secret, but with online counseling, cases have occurred where people' $s$ personal information has been revealed outside of the counselor' s office. Therefore, we designed a system that is relatively safe. The designer of the security system focused on making sure that everything was safe for the online counseling system, but most people are not overly concerned about it. People that were interviewed did not know much about online security, but had the interviewees been more conscious of security issues, the results of the interviews probably would have been different.

The following results were obtained using this system. Most people wanted to find out as much as possible about their counselor. If they knew how many people talked to this counselor, they felt more confident and could trust the counselor more. Because they know what' $s$ bothering them, people can see clearly what their problem is. Designing a questionnaire with many choices might be difficult.

The reason people want to be able to look at the emails they send is so they can better understand and organize how they feel about themselves.

The people wanted the words to be closer to the center of the page.

The system was adjusted to be in line with the results of the interviews. These interviews generated much information from users. Their opinions were reflected when designing the system.

\section{Correlation Analysis of Interviews}

We conducted further interviews with 23 people and categorized the results from the interviews into four factors. Table II shows the results of the correlation analysis based on a survey of our research and the four factors using SPSS 15.0J.

Considering correlation coefficient between' Easy to use ' and' Design, ' it was concluded to be insignificant according to the table $(\mathrm{r}=-.201(\mathrm{df}=23), \mathrm{ns})$. Just because
TABLE I.

RESULT OF INTERVIEWS REGARDING THE OVERALL MAGE OF ONLINE COUNSELING STYLES.

\begin{tabular}{|c|c|}
\hline \multicolumn{2}{|l|}{ 1. What do you think of online counseling? } \\
\hline It is easy to access. & 3 \\
\hline It does not take much time. & 2 \\
\hline \multicolumn{2}{|c|}{$\begin{array}{l}\text { 2. What information do you want to know when you use } \\
\text { online counseling? }\end{array}$} \\
\hline I want to see the counselor's face. & 5 \\
\hline $\begin{array}{l}\text { I want information about the counselor's } \\
\text { background. }\end{array}$ & 7 \\
\hline \multicolumn{2}{|l|}{$\begin{array}{l}\text { 3. Do you have any concerns regarding the security of } \\
\text { online counseling? }\end{array}$} \\
\hline I'm not really concerned about their security. & 2 \\
\hline $\begin{array}{l}\text { I don't trust the security system now being } \\
\text { used. }\end{array}$ & 1 \\
\hline $\begin{array}{l}\text { If there is a warning concerning the security, I } \\
\text { will read it. }\end{array}$ & 1 \\
\hline \multicolumn{2}{|l|}{ 4. What do you think of our online counseling system? } \\
\hline $\begin{array}{l}\text { I want to know many things about the } \\
\text { counselor. }\end{array}$ & 5 \\
\hline $\begin{array}{l}\text { I want to know how many people are using this } \\
\text { system. }\end{array}$ & 3 \\
\hline $\begin{array}{l}\text { I would like to have more boxes to check } \\
\text { regarding what's troubling me. }\end{array}$ & 3 \\
\hline $\begin{array}{l}\text { I would like to have everything written closer } \\
\text { to the center of the page. }\end{array}$ & 2 \\
\hline $\begin{array}{l}\text { I want to be able to check the e-mail the } \\
\text { counselor sent. }\end{array}$ & 2 \\
\hline
\end{tabular}

TABLE II.

RESULTS OF CORRELATION ANALYSIS $(\mathrm{N}=23)$.

\begin{tabular}{|l|c|c|c|c|}
\hline & $(1)$ & $(2)$ & $(3)$ & $(4)$ \\
\hline (1) Easy to use & 1 & -.201 & -.103 & .055 \\
\hline (2) Design & & 1 & -.103 & .055 \\
\hline $\begin{array}{l}\text { (3) How well a } \\
\text { person can operate } \\
\text { a computer }\end{array}$ & & & 1 & -.018 \\
\hline (4)Trust & & & & 1 \\
\hline
\end{tabular}


it was easy to use did not mean that the design was considered to be good. The reason why the correlation coefficient was considered insignificant, was not because the system failed to support the user to the point where it was easy to use. To say this another way, this system ' $\mathrm{s}$ user interface was effective in fulfilling the user' s requirement. Also, it is not the design so much as how well the basic system can function to support online counseling. Regarding online counseling, the user' s purpose is quite clear, so if the user' $\mathrm{s}$ will is strong enough to want to use this system for online counseling, the design is not terribly important. The basic design of this system is not like those used in game software for entertainment and it is also different from a commercial web site.

Considering the correlation coefficient between' Easy to use' and How well a person can operate a computer,' it was concluded to be insignificant according to the table ( $r$ $=-.103(\mathrm{df}=23), \mathrm{ns})$. Concerning how easy the system is to use, the system has cleared the next two points. First, even beginners who have made no preparation will find this system easy to use. Second, generally speaking, the system was designed to such an extent that it would be easy to understand, so sometimes users feel they are doing wasteful operations, but this original system was not meant to be this way.

Considering the correlation coefficient between' Easy to use' and' Trust,' it was concluded to be insignificant according to table $(\mathrm{r}=.055(\mathrm{df}=23)$, ns $)$. Even though this system is easy to use, users will find that trust comes from other factors. To obtain trust, we need to use code numbers as much as possible, and the important thing is to think separately about the design and the ease of use.

From the correlation analysis results, the system design was not poor to the point where it was hard to use. However, contrary to our expectations, all items ware concluded to be insignificant.

\section{Online Web Counseling System}

In this section we present our online Web counseling system by the use of agile software development methodologies.

\section{A. System Overview}

Figure 1 shows how the counseling system is configured. Counseling took place by sending mail mutually on the Web. All messages are stored in a database of the system to prevent the information from leaking outside. Moreover, the system automatically sends notification mail to counselors. This will enable reporting consultation mail to counselors without logging into the system. And the counselors respond to the clients for consultation after login. The reason why Email is just used for notification is that the counseling content in Email is leaked by intercepting mail server communication or computer virus. Figure 2 shows the contents of an auto notification mail that is sent.

Clients access the system by a Web browser and input contents of consultation to their own counselor after

\section{Reply Reply all Forward}

\section{You have got a CS mail !}

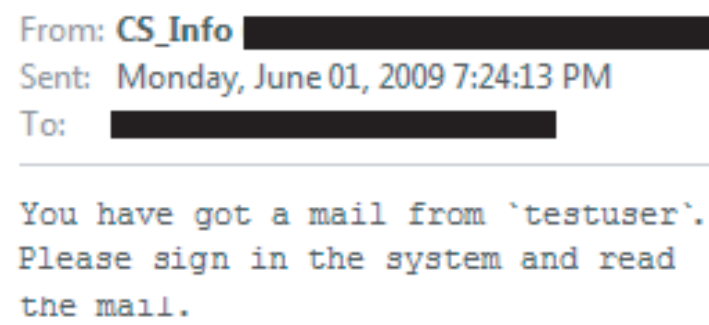

Figure 2. Notification mail.

logging in. When the mails are sent, a counselor receives the message of consultation. The counselors respond to the clients for the consultation.

Our system is implemented on Linux and uses Tomcat as the application server, MySQL as the database management system, and Post fix as the mail server. The system does not limit the time. Because clients can send and receive at a time that is most convenient for them, they can feel reassurance - they are connected to someone. Moreover, clients sometimes feel like they can talk about things over the internet that they cannot talk about face to face.

From the interview results, we see that people had a good impression of online counseling, and nobody had a bad impression. Most people wanted to know about their counselor's background because they could not see their counselor' s face, were revealing many sensitive personal things, and feel anxious. Therefore, we provide the web pages for detailed information on counselors. Moreover, these interviews generated much information from users, for example, layout, color, function and so on. Their opinions were reflected in the online counseling system. Therefore, clients can feel more confident and trust the counselor and the system.

\section{B. Authorities and Their Functions}

There are authorities for each user in the system, and the utilizable operation differs. The authorities and their functions are as follows.

(1) Authority: administrator

Functions:

- counselor registration.

- counselor assignment.

- confirmation of applications for counselors

- confirmation of the account list

- auto notification mail sending $\log$

(2) Authority: counselor

Functions:

- mail browsing. 


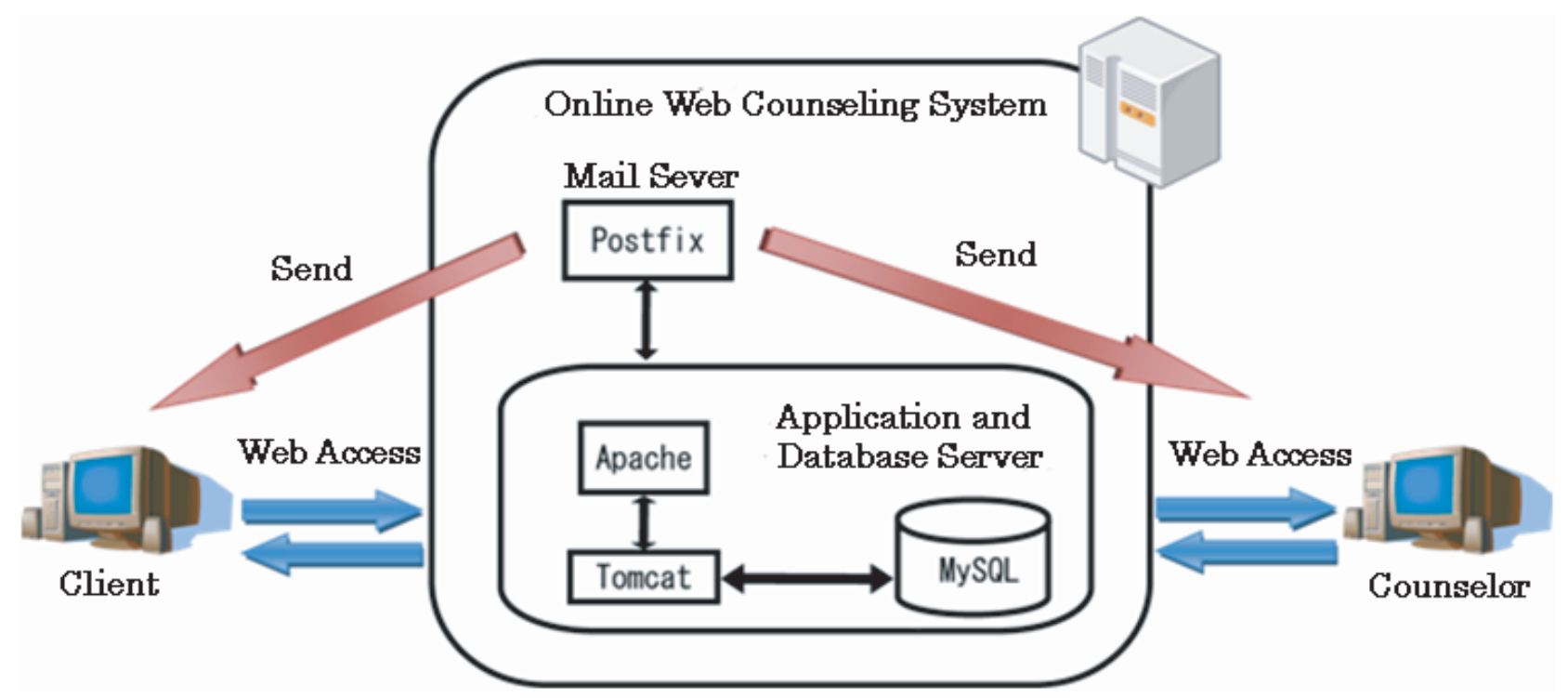

Figure 1. System configuration.

- mail sending.

- confirmation of access logs

- change in registration information

- PDF up/downloading

(3) Authority: client

Functions:

- mail browsing

- mail sending

- change in registration information

- counselor application

Users that have administrator authority can manage the counseling system. They can assign a client to a counselor. In our system, the only person that can view the contents of a consultation is the assigned counselor.

Users that have counselor authority are paid specialists in counseling and can provide counseling to clients. Figure 3 shows a screenshot of a received mail list page for a counselor.

\begin{tabular}{|c|c|c|c|c|c|}
\hline \multicolumn{2}{|l|}{ tration screen } & & & & \\
\hline \multicolumn{6}{|c|}{ Administration screen (test1234) } \\
\hline \multicolumn{6}{|c|}{ Change for resistration in formation $/$ Incomins mail $/$ Pdf upload $/$ Los of access $/$ Cancel } \\
\hline \multicolumn{6}{|c|}{ Incoming mail } \\
\hline Time sent & ID & Title & Nick name & Read & Return \\
\hline $2009-06-0119: 26.52 .0$ & $\begin{array}{c}\text { testuser } \\
\text { [info }\end{array}$ & $\begin{array}{l}\text { test } \\
\text { Read }\end{array}$ & test & read & $\begin{array}{c}\text { return } \\
\text { return mail }\end{array}$ \\
\hline $2009-06-01 \quad 19: 26: 13.0$ & $\begin{array}{c}\text { testuser } \\
\text { [nfo }\end{array}$ & $\begin{array}{l}\text { test } \\
\text { Read }\end{array}$ & test & read & $\begin{array}{l}\text { return } \\
\text { return mail }\end{array}$ \\
\hline
\end{tabular}

Figure 3. Received mail list page for counselor.

Users that have client authority are people that receive counseling. Anyone can acquire an account with client authority. If a counselor for a client is not assigned, the user cannot use counseling functions.

\section{EVALUATION}

We evaluated our online Web counseling system by conducting a survey in the form of a questionnaire. The test users were all graduate students at Toyo University.

\section{A. Questionnaire Design}

First of all, we conducted a pre-survey to decide question items. The six people interviewed for the presurvey are all students at Toyo University. We have about 10 question items written by them and a total of 59 question items were adduced. On the basis of their question items and category classification method, we conducted a gathering of scientific data, a card production, group classification and graphic explanation. Their question items are classified in 5 groups and each group is given a name as a factor: "Easy to use", "Design", "Trust", "Degree of satisfaction" and "Image". Figure 4 shows each group and part of the question items.

We created a system evaluation questionnaire from the pre-survey. The questionnaire consists of 18 questions: 9 choice questions and 9 written questions. Table III shows part of the questions and its results.

Question 1 is a question to grasp how often users use personal computers and measures relation of skills and evaluations. There is not Question 1 in the pre-survey, however we added the question for skill evaluation.

Question 2 is a question for easy to use. Since there are ease to operate, speed of behavior, easy to get information and so on, we distilled their views into a question in terms of easy to use.

Question 4 is a question for trust. There are needs for conducting a survey of trust of a system from the presurvey.

Question 6 is a question for design. Since there are size of string, font, layout of display and so on, we distilled their views into a question in terms of design. 
【Easy to use】

- When you use the system, are you required additional work?

- Do you immediately get information you want? 【Design】

- Is the screen easily viewable?

- Are the text and the font easily viewable? 【Trust】

- Is personal information steadily guarded?

- Do I have any qualms about system security? 【Satisfactory degree】

- Are there functions you want?

- Do you expect the future system

【Image】

- What image did you have before user registration.

- What gap are there or do you feel compared with image before you use the system.

Figure 4. Example of question items.

Question 8 is a question about the degree of satisfaction of the online counseling system. The question is created to survey if the degree of satisfaction is enough, what functions the system demands and what parts of the system is not enough.

Question 12 is a question for speed of response connected with easy to use. The question is created to survey how users feel stress and how ease to use are influenced by speed of response.

Question 14 is a question for representation of writing. The question is included in ease to use and design, however, the question is created as independent question to survey how ease to use is influenced by representation of text.

Question 16 is a question about the image of online counseling system. The question is created to survey what image uses have.

\section{B. Carry Out Questionnaire Survey}

We carried out a questionnaire survey of our system to students of the software science laboratory in Toyo University.

In question 1, the usage frequency of questionnaire 1 shows that the usage frequency of PC or Internet for the questioners was high because the questioners were student.

Question 2 shows an ease of using the online counseling system. Comments of "user-friendliness" was higher than "slightly hard to use". We received comments such as "Easy to use and simple because number of menus is not too many", "Easy to understand because the system is simple" and "Font size is small at commonly use area" from free description form. These comments are linked to the display of the system.

Many answers "less-creditworthy" were obtained from question 4. Therefore it is unclear how user data is treated in the system, users may feel uneasy about the system.

As comment below "Warm color background is comfortable" and "The system is simple and user-friendly", we obtained a relatively-good comment for the design in question 6. [?] shows that cold colors such as light blue, white and blue have a calming effect.

As for question 8 , there were some comments about the system having limited functions. We obtained comments such as "telephone and video phone function are needed. mobile function is also needed." and "mail communication is hard to communicate on a real-time basis". This system targets workers stationed abroad, therefore we adopted a message based system to resolve the time lag. It is true that our system can not respond in real time when users have troubles, chat or video phone functions need to be developed.

In question 12, comments for response speed were good. The current system is based on text, system behavior is comfortable.

We received good comments about text representation in question 14.

About system image, there were "good" and "poor" in fifty-fifty in question 16. Such as positive comments as "users can consult a counselor anonymously without face to face interaction" and "users can contact a counselor at home" were obtained. However there were negative comments "feel uneasy about individual information", "users have reservations against advice reliability from counselors", "users are worried whether counselors reply or not", and so on.

\section{Analysis of Questionnaire}

We performed correlation analysis of the questionnaire. Table IV shows the result of correlation analysis for the questionnaire.

We obtained three correlations. First, usability and satisfaction have a relation. If systems can be used without stress, users satisfaction for the system will grow. The second correlation is the relation between text representation and system image. The more systems have articulate text representation, the more understanding users can obtain. The third correlation is proficiency and usability. Users with proficiency get the impression that the system is awkward to use.

Therefore we plan to upgrade our system by modifying the system from the viewpoint of usability and text representation, then we think users can decrease feelings of resistance.

However improvement of usability cause debasement of proficiency. Our system's target is for the beginner and the experienced. By reason that usability for users who are unfamiliar with PC is also important, it is important to add 
TABLE III.

EXAMPLE OF QUESTION ITEMS.

\begin{tabular}{|c|c|c|c|c|}
\hline \multirow{3}{*}{$\begin{array}{l}\text { Question } \\
\text { Q1. How often do you use internet } \\
\text { or personal computer? }\end{array}$} & \multicolumn{4}{|c|}{ Answer } \\
\hline & Always & Often & Rarely & Never \\
\hline & 16 & 6 & 2 & 0 \\
\hline \multirow[t]{2}{*}{ Q2. Is the system easy to use? } & Very easy & Easy & A little hard & Hard \\
\hline & 0 & 14 & 10 & 0 \\
\hline \multirow[t]{2}{*}{ Q4. Do you trust the system? } & Large trust & Trust & Little trust & Not trust \\
\hline & 0 & 9 & 14 & 1 \\
\hline \multirow{2}{*}{$\begin{array}{l}\text { Q6. What do you think of the } \\
\text { design of the system? }\end{array}$} & Great & Good & Poor & Bad \\
\hline & 0 & 17 & 6 & 0 \\
\hline \multirow{2}{*}{$\begin{array}{l}\text { Q8. Are functions of the system } \\
\text { enough? }\end{array}$} & Large enough & Enough & A little short & Short \\
\hline & 0 & 10 & 13 & 0 \\
\hline \multirow{2}{*}{$\begin{array}{l}\text { Q12. What do you think about } \\
\text { speed of response.? }\end{array}$} & Great & Good & Poor & Bad \\
\hline & 5 & 14 & 3 & 1 \\
\hline \multirow{2}{*}{$\begin{array}{l}\text { Q14. What do you think of the text } \\
\text { of the system? }\end{array}$} & Great & Good & Poor & Bad \\
\hline & 5 & 15 & 4 & 0 \\
\hline \multirow[t]{2}{*}{ Q16. What image do you have? } & Great & Good & Poor & Bad \\
\hline & 1 & 10 & 10 & 1 \\
\hline
\end{tabular}

TABLE IV.

RESULT OF CORRELATION ANALYSIS FOR TABLE III

\begin{tabular}{|c|c|c|c|c|c|c|c|c|}
\hline & proficiency & usability & authenticity & design & satisfaction & response speed & text representation & system image \\
\hline proficiency & 1 & -.418 & -.314 & -.054 & -.224 & .094 & .364 & .187 \\
\hline usability & & 1 & .051 & .078 & $.524 *$ & -.364 & -.219 & .000 \\
\hline authenticity & & & 1 & .015 & .082 & .107 & -.165 & .187 \\
\hline design & & & & 1 & .302 & .184 & .258 & .023 \\
\hline satisfaction & & & & & 1 & -.371 & -.061 & .187 \\
\hline response speed & & & & & & 1 & .289 & .187 \\
\hline text representation & & & & & & & & \\
\hline system image & & & & & & & & $.488 *$ \\
\hline
\end{tabular}

functions for the experienced without hindering usability for a beginner. [5] and [6] show that there are differences of impressions about the online counseling system among countries, especially for colors of the system, and demand for the system, respectively.

The usability survey was performed for clients and counselor. There was a lot of feedback on the system design from test users. From the correlation analysis results, we see that the system design was not poor to the point where it was hard to use. To say this another way, this system's user interface was effective in fulfilling the user's requirements. If the system has a certain level of design, users require other things, such as functions, because the purpose of use is clear. It is different from game software for entertainment and commercial web sites. Moreover, generally speaking, the system was design to such an extent that it would be easy to understand, so sometimes users feel they are performing wasteful operations, but this original system was not meant to be this way. In addition to these, to obtain trust, it is necessary to think separately about the design and the ease of case.

\section{CONCLUSION}

We have developed and operated an online Web counseling system by use of agile software development methodologies to prevent mental health problems from worsening by early negligences for those assigned overseas in Asia. The system is constructed in cooperation with a clinic. The system can offer mental healthcare services by Japanese professionals working in Japan to a lot of Japanese nationals that work in foreign countries. The central focus is on China and Taiwan. All messages are stored in the data base of the system to prevent the information from leaking outside. Counselors are able to provide a consultation via the Web without going to the client's location and the system does not limit the time. 
We have developed an effective online counseling system using statistical methods

The results of the system evaluation showed that demand for original functions outside the system design are high under the system that has a clear intended purpose. It is also important to make someone feel less inhibited by increasing security and improving the system image. Information secrecy and security carries great weight in online counseling systems that are closely associated with mental issues.

In the future, we plan to improve the user interface from the psychological standpoint and to increase the confidentiality and security. We aim to establish counseling services over the Internet, with a focus on psychological testing.

\section{ACKNOWLEDGMENT}

This research was partially supported by the INOUE ENRYO Memorial Foundation for Promoting Sciences. The authors thank the participants in the evaluation for valuable comments. We thank the clinic for the data and valuable discussions.

\section{REFERENCES}

[1] Kaoru Sugita, Noriki Uchida, Akihiro Miyakawa, Giuseppe De Marco, Arjan Durresi, Leonard Barolli, "Performance Evaluation of WWWConference System for Supporting Remote Mental Health Care Education," Parallel and Distributed Systems, Proceedings of the 11th International Conference on Parallel and Distributed Systems (ICPADS'05), vol. 1, pp. 271-277, 2005.

[2] Mayumi Hori, Masakazu Ohashi, "Applying XML Web Services into Health Care Management," Proceedings of the 38th Annual Hawaii International Conference on System Sciences (HICSS'05), vol. 6, pp. 155a-155a , 2005.

[3] Ramesh Farzanfar, Sophie Frishkopf, Robert Friedman,Kevin Ludena, Evaluating an automated mental health care system: making meaning of human-computer interaction, Computers in Human Behavior, Volume 23, pp. 1167-1182, 2007.

[4] Yasunori Shiono, Takaaki Goto, Tetsuro Nishino, Chieko Kato and Kensei Tsuchida, "Development of Web Counseling System," Proceedings of the 12th International Conference on Network-Based Information Systems, pp. 370375, IEEE Computer Society, August 2009.

[5] Heliang Zhuang, Kensei Tsuchida, Chieko Kato, Yujiro Ishimura and Takehide Goto, "International Comparison of Needs of Consumers Towards On-Line Counseling's Design," Journal of the Visualization Society of Japan, Vol. 30, Suppl. No. 1, Proceedings of the 38th Symposium on Visualization, E116, pp. 161-162, 2010 (in Japanese).

[6] Satoshi Yoshinuma, Yujiro Ishimura, Taishi Kikuchi, Heliang Zhuang, Kensei Tsuchida, Chieko Kato, Takehide Goto, "International Comparison of the Needs of Consumers towards Online Counseling -between Japan and China-," Journal of the Visualization Society of Japan, Vol. 30, Suppl. No. 1, Proceedings of the 38th Symposium on Visualization, C202, pp. 317-318, 2010 (in Japanese).

[7] Journal of Emerging Technologies in Web Intelligence Special Issue: E-health Interoperability, Volume 1, Number 2, pp. 107-171, November 2009.

[8] D. A. Norman and S. W. Draper, User Centered System Design. Lawrence Erlbaum, 1986.
[9] H. Lindstrom and M. Malmsten," User-centred design and agile development: Rebuilding the swedish national union catalogue," Code4Lib Journal, no. 5, 2008.

[10] M. Aoyama, "Web-Based Agile Software Development," IEEE SOFTWARE, Volume 15, Issue, 6, pp. 56-65, 1998.

[11] Wookjin Lee, Sanghyun Park, Keeyoull Lee, Chunwoo Lee, Byungjeong Lee, Woosung Jung, Taeksu Kim, Heechern Kim, Chisu Wu, "Agile Development of Web Application by Supporting Process Execution and Extended UML Model," Proceedings of the 12th Asia-Pacific Software Engineering Conference, pp. 193-200, 2005.

[12] Keeo Lee, "An Agile Method for Web Applications in Dynamic Requirements," Proceedings of the Fourth International Conference on Networked Computing and Advanced Information Management, vol. 2, pp. 178-182, 2008.

[13] Hu Ran, Wang Zhuo, Hu Jun, Xu Jianfeng, Xie Jun, ”Agile Web Development with Web Framework," Proceedings of the 4th International Conference on Wireless Communications, Networking and Mobile Computing, pp. 1-4, 2008.

Chieko Kato received M.A. from Tokyo University and Dr.Eng. degree from Hosei University in 1999 and 2007, respectively. She served 2003 to 2006 as assistant professor at the Oita Prefectural Junior College of Arts and Culture. She currently teaches at Toyo University, which she joined in 2006 as an assistant professor, and was promoted to associate professor in 2007. Her research areas include clinical psychology and psychological statistics. She is a member of IEICE Japan, Design Research Association, the Japanese Society of Psychopathology of Expression and Arts Therapy and the Japanese Society of Psychopathology of Expression and ArtsTherapy.

Yasunori Shiono received M.E. and Dr.Eng. degrees from Toyo University in 2006 and 2010 respectively. He is currently an Assistant Professor at Toyo University. His research interests include graph algorithms, graph grammars, fuzzy theory and software development environments. He is a member of IEICE Japan, JSSST, JSIAM and IEEE.

Takaaki Goto received M.E. and D.E. degrees from Toyo University in 2003 and 2009 respectively. He is currently an Project Assistant Professor in the University of ElectroCommunications. His main research interests are applications of graph grammars, visual languages, and software development environments. He is a member of the IEICE Japan and IEEE.

Kensei Tsuchida received M.S. and D.S. degrees in mathematics from Waseda University in 1984 and 1994 respectively. $\mathrm{He}$ was a member of the Software Engineering Development Laboratory, NEC Corporation in 1984-1990. From 1990 to 1992, he was a Research Associate of the Department of Industrial Engineering and Management at Kanagawa University. In 1992 he joined Toyo University, where he was an Instructor until 1995 and an associate professor from 1995 to 2002, and since 2002 he has been a Professor of the Department of Information and Computer Sciences. He was a visiting associate professor of the Department of Computer Science at Oregon State University from 1997 to 1998 . His research interests include software visualization, human interface, graph languages, and graph algorithms. He is a member of the IEICE Japan, IEEE Computer Society and ACM. 